\begin{tabular}{|c|c|}
\hline $\begin{array}{l}\text { Chemistry of } \\
\text { Metals and Alloys }\end{array}$ & $\begin{array}{l}\text { Chem. Met. Alloys } 4 \text { (2011) } 188-199 \\
\text { Ivan Franko Notional Universit of IViv } \\
\text { www..chemetal-journal. org }\end{array}$ \\
\hline
\end{tabular}

\title{
Effect of particle size on the chemical composition of Ti-Ni-base spark erosion powder obtained in liquid argon
}

\author{
Gennady MONASTYRSKY ${ }^{1,3 *}$, Patrick OCHIN ${ }^{2}$, Guillaume Y. WANG ${ }^{2}$, Victor KOLOMYTSEV ${ }^{3}$, Yuri KOVAL $^{3}$, \\ Andriy GILCHUK ${ }^{1}$, Vitaliy TINKOV ${ }^{3}$, Anatoliy SHCHERBA ${ }^{4}$, Sergey ZAHARCHENKO ${ }^{4}$ \\ ${ }^{1}$ National Technical University of Ukraine "KPI”, Peremogy Ave. 37, UA-03506 Kyiv, Ukraine \\ ${ }^{2}$ Institut de Chimie et des Matériaux Paris-Est, ICMPE-CNRS, 2-8 Rue Henri Dunant, F-94320 Thiais, France \\ ${ }^{3}$ Institute of Metal Physics of NAS of Ukraine, Vernadsky Ave. 36, UA-03142 Kyiv, Ukraine \\ 4 Institute of electrodynamics of NAS of Ukraine, Peremogy Ave. 56, UA-03680 Kyiv, Ukraine \\ * Corresponding author. Tel.: +380-97-4068512; fax: +380-97-4068512; e-mail: monag@imp.kiev.ua
}

Received November 19, 2010; accepted December 28, 2011; available on-line August 17, 2012

Ti-Ni-Zr and Ti-Ni-Hf powders were obtained by the spark-erosion method in liquid argon from preliminary melted shape memory master alloys. The morphology of the particles with typical sizes between 5 and $50 \mu \mathrm{m}$, their surface as well as the cross-section structure are very similar to typical ones of gas atomized powders. The internal structure of such particles of both compositions is transient between cellular and equiaxed-type. Nanosized particles of spherical shape usually gather in agglomerates. The chemical compositions of micron-sized particles were investigated very carefully. It was statistically well proven that while the compositions of particles with sizes more than $10 \mu \mathrm{m}$ are close to the composition of the master alloy, the compositions of the smallest particles are drastically different. The results obtained allow claiming that such important changes in the chemical compositions of powders are connected with the different rate of evaporation of elements due to their different vapor pressures. The size dependence of the composition is related to the different cooling rate of particles of different sizes.

Powders / Gas atomized powders / Spark-erosion method / Shape memory alloys / Spark plasma sintering / Ti-Ni-Hf / Ti-Ni-Zr

\section{Introduction}

The conventional industrial gas or water atomization method of production of metal powders virtually allows manufacturing powders of any composition with a wide size distribution from 2 to $500 \mu \mathrm{m}$ [1-4]. The method is not economically viable for the largescale production of powder particles of less than several microns. Mechanical alloying [5-8] and electro-explosion of wires $[9,10]$ give high production yields of nanosized metal powders. Unfortunately, the capital cost of electrical power supply, starting wire material can be relatively expensive. Various modifications of the method of condensation from the vapor state allow obtaining nanopowders, the compositions of which are far from the master alloys [11-13]. Spark erosion is probably the most versatile technique available for producing the particles of metals, alloys, compounds with particle diameters from a few $\mathrm{nm}$ to $>100 \mu \mathrm{m}[14,15]$. Powder particles of $\mathrm{Ni}-\mathrm{Al}$ [16] shape memory alloys, pure $\mathrm{Ni}[17,18]$, ferromagnetic Mn-Al-C [19], Co50-Fe50 [20], $\mathrm{Ni}_{3} \mathrm{Fe}$ [21], amorphous soft magnetic Fe-Si-B, Nd-Fe-B $[15,22]$, giant magnetostrictive alloy Fe83-Ga17
[18,23, references in 15], W, Ta, Fe, Ti carbides [24, references in 15], Ni-Mn-Ga [14,25], Ti-Ni-Cu, $\mathrm{Ti}-\mathrm{Ni}-\mathrm{Cu}-\mathrm{Zr}$ [14,26-29], $\mathrm{MgO}$ oxide [21], different types of Fe nitrides [30], U-Mo [31], the Ni-based superalloy René 95 [32] and $\mathrm{Ti}-\mathrm{Zr}-\mathrm{Ni}$ hydrogen storage alloys [33] have already been produced by this method. There are a few advantages that make this method very attractive for the laboratory scale production. It does not require any crucibles and there is no limit imposed by melting temperatures. The setup and basic apparatus are quite simple, and the modest power required is used efficiently.

The spark erosion process maintains repetitive spark discharges among small pieces (chunks) of prealloyed materials (master alloy) immersed in a dielectric liquid. Spark discharges induce highly localized melting or vaporization of the material $[15,18,29,32,34]$. The powder particles are produced by associated mechanisms such as quenching of molten droplets, condensation of vapor in the dielectric liquid and by mechanical breaking of the chunks during the processing. Usually the last mechanism, which is very similar to ball milling, produces a minor fraction of powders, except in the 
specific case of very brittle initial materials like $\mathrm{Ni}-\mathrm{Mn}-\mathrm{Ga}$ [14]. The quenching in situ from the liquid state, as well as the condensation from the vapor phase, produces round particles. It is considered that a very high cooling rate is required for the preparation of amorphous or nanocrystalline particles [15]. The cooling rate estimated indirectly in [15] was $10^{6} \mathrm{~K} / \mathrm{sec}$ for the particles processed in $\mathrm{H}_{2} \mathrm{O}$ and dodecane. On the other hand the use of carbon- or oxygen-bearing dielectric liquids provokes the formation of oxides, carbides and other compounds of the master alloy elements, as it was clearly illustrated in $[17,26]$. The nanosized particles are strongly influenced by products of the decomposition of dielectric liquids [17].

In previous work [29] $\mathrm{Ti}-\mathrm{Ni}-\mathrm{Cu}-\mathrm{Zr}$ powders were produced by the spark erosion method in liquid argon. It was found that the finest particles are rather a mixture of $\mathrm{Ti}$ and $\mathrm{Ni}$ powders (or their oxides) than the intermetallic compound of the master alloy. In any case the composition of the finest particles, which are presumably produced by the condensation of vapor phase, is far enough from the composition of the prealloyed material. The aim of the current work was to carefully verify the composition of micron-sized particles of $\mathrm{Ti}-\mathrm{Ni}$-base alloys, which are produced by quenching from the liquid state, and compare the results obtained for gas and liquid atomized powders. The question is very important, especially in the case of $\mathrm{Ti}-\mathrm{Ni}-\mathrm{Cu}-\mathrm{Zr}$ and $\mathrm{Ti}-\mathrm{Ni}-\mathrm{Hf}$ shape memory alloys, the properties of which drastically depend on the composition.

\section{Experimental}

Commercially pure $\mathrm{Ti}, \mathrm{Ni}, \mathrm{Cu}, \mathrm{Hf}$ and $\mathrm{Zr}$ (99.9\%) were used for the production of alloys by induction melting. The chemical composition of the bulk alloy was Ni46.7-Ti49.2-Zr3.4-Cu0.7 at.\%. Rods of Ni49.87-Ti40.25-Hf9.44-Zr0.30-Cu0.14 at.\% (hereafter referred to as $\mathrm{Ni}-\mathrm{Ti}-\mathrm{Hf}$ ) with a diameter of $6 \mathrm{~mm}$ were produced by AMT (Belgium). The $\mathrm{Ti}-\mathrm{Ni}-\mathrm{Cu}-\mathrm{Zr}$ ingot was hot-rolled at $900^{\circ} \mathrm{C}$ to a thickness of $\sim 3 \mathrm{~mm}$. The rolled sheet was annealed at $1000^{\circ} \mathrm{C}$ for $6 \mathrm{~h}$. Part of the annealed sheet was ground into chunks of $2-4 \mathrm{~mm}$. Those pieces, as well as crushed rods, were used as charge for the cell of the spark erosion apparatus. The remaining $\mathrm{Ni}-\mathrm{Ti}-\mathrm{Cu}-\mathrm{Zr}$ sheet, machined into two rectangular plates, and $\mathrm{Ni}-\mathrm{Ti}-\mathrm{Hf}$ rods were used as electrodes for the apparatus.

The general principle of spark-erosion processing was described in details in $[14,15,17]$ and involves the application of a heavy current ( 1000 A) between two electrodes and a lot of pieces (chunks) prepared from the pre-alloyed material. All are immersed in a dielectric refrigerant inside a container. Many electrical discharges simultaneously appear between the chunks of material. When an electrical spark collapses, molten particles are ejected from these boiling regions, and then quenched in situ in liquid argon. After the spark erosion processing, the powders were placed in hexane to prevent rapid oxidation and explosion.

$\mathrm{Ni}-\mathrm{Ti}-\mathrm{Hf}$ powders were sintered by the spark plasma sintering method (SPS). The SPS method is an express method of sintering, which allows sintering powders within 10 minutes in vacuum $(10-200 \mathrm{~Pa})$ or inert gas atmosphere. It realizes simultaneously relatively high pressure, high sintering temperature and a heavy current passing through the sample, which destroys the oxidation film on the powder surface, providing good sintering $[35,36]$. Part of the $\mathrm{Ni}-\mathrm{Ti}-\mathrm{Hf}$ powders was heat treated in hydrogen gas atmosphere at $380^{\circ} \mathrm{C}$ for $3 \mathrm{~h}$.

The crystal structure of the bulk, powder and sintered materials was investigated at room temperature using the X-ray Debye-Scherrer method. The device was a diffractometer Philips PW1830 with $\mathrm{Co} \mathrm{K} \alpha_{1,2}$ radiation and equipped with a Multi-Purpose X-Ray Diffraction System from PANalytical (XPert PRO MPD). The refinement was made using the shareware program Maud. The morphology of the powder particles was studied by optical microscopy (Carl Zeizz Axelvert 40 MAT). The fine structure of the surface and cross-sections of the powders, as well as the local chemical composition, were investigated by scanning electron microscopy using different instruments: LEO 1530 equipped with an energy dispersive X-ray spectrometer PGT PRISM 2000 (Ge), JSM-6490LV (Jeol) equipped with an Energy Dispersive X-ray (EDX) spectrometer INCA Energy 450 (Oxford Instruments), JAMP-9500F (Jeol) equipped with an EDX spectrometer INCA PentaFETx3 (Oxford Instruments), and PEMMA-102 equipped with an EDX spectrometer (Selmi, Ukraine). The smallest particles of the Ni-Ti-Hf powder were investigated with a high performance analytical microscope Tecnai ${ }^{\mathrm{TM}}$ G2 F20.

\section{Results}

\section{i) $X$-ray investigation}

According to the results of the X-ray investigation of the $\mathrm{Ti}-\mathrm{Ni}-\mathrm{Cu}-\mathrm{Zr}$ powders, which have already been presented elsewhere [29], the powders contain the B2 phase ( $a=2.998 \AA$; PDF\#18-0899), the monoclinic (martensite) phase B19' $(a=2.889 \AA, b=4.120 \AA$, $c=4.622 \AA, \beta=96.8^{\circ}$; PDF\#27-0344) and the cubic phase $\mathrm{Ti}_{2} \mathrm{Ni} \quad(a=11.27 \AA$; PDF\#18-0898). Similar results were obtained for the $\mathrm{Ni}-\mathrm{Ti}-\mathrm{Hf}$ powder (Fig. 1a). The calculated lattice parameters of the phases are the following: B19', $a=2.979 \AA$, $b=4.106 \AA, c=4.796 \AA, \beta=100.2^{\circ}$, which is close to that found in [37]; $\mathrm{B} 2, \quad a=3.073 \AA$; $\quad \mathrm{Ti}_{2} \mathrm{Ni}$, $a=11.49 \AA$. It was established that the quantity of martensitic phase was $44 \pm 5 \%$, austenitic phase B2 $35 \pm 4 \%$ and $\mathrm{Ti}_{2} \mathrm{Ni} 21 \pm 3 \%$. 


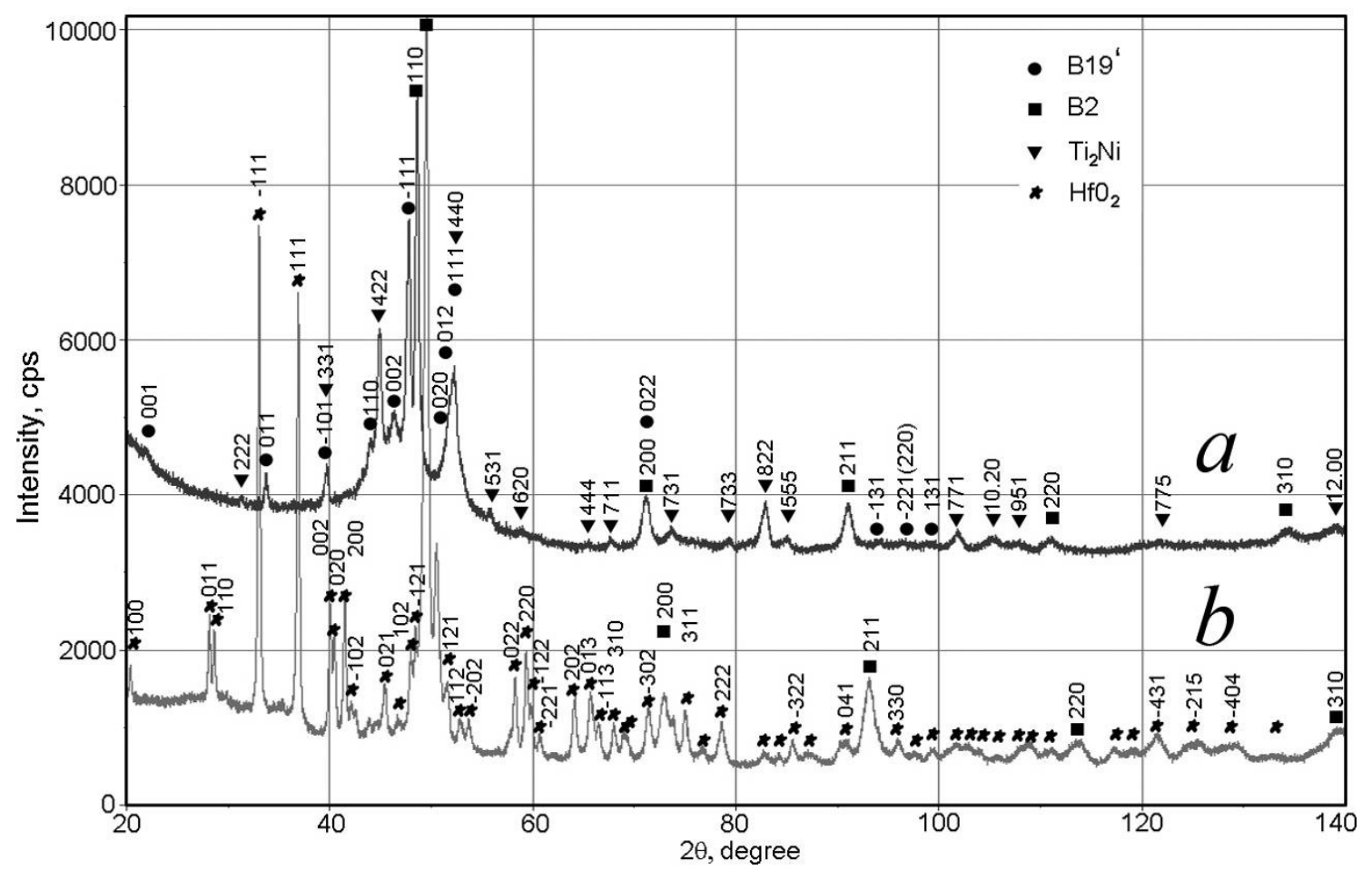

Fig. 1 X-ray spectrum of powder $(a)$ and sintered $(b)$ samples.

After spark plasma sintering the dominating peaks in the spectra of $\mathrm{Ti}-\mathrm{Ni}-\mathrm{Hf}$ belonged to monoclinic $\left(P 2_{1} / c\right) \mathrm{HfO}_{2}(a=2.889 \AA, b=4.120 \AA, c=4.622 \AA$, $\beta=96.8^{\circ}$; PDF\#06-0318) as it is seen on Fig. $1 b$. In addition, two B2 phases with similar lattice parameters ( $a=2.96 \AA$ and $a=3.01 \AA$ ) were found. Such dramatic changes in the X-ray spectra could be explained by the high vacuum (20-100 Pa), which was achieved during the spark plasma sintering. Thus the $\mathrm{Ni}-\mathrm{Ti}-\mathrm{Hf}$ powder was strongly oxidized after SPS, mainly due to the high reactivity of hafnium. The processes of sintering are the matter of other articles and will be only partially described in the discussion section of this article.

According to the X-ray studies, in the Ti-Ni-Hf powder the composition of the B19' phase calculated from the occupation numbers was Ni50-Ti26-Hf24 at.\%, while that of the B2 phase was Ni48-Ti45-Hf7 at.\% and the composition of the (Ti,Hf $)_{2} \mathrm{Ni}$ phase was Ni33-Ti50-Hf17 at.\%. Thus the strong chemical heterogeneity, which was found in Ti-Ni-Hf powders, was expressed through a B19' phase enriched in hafnium and a B2 phase with less hafnium. This is an expected result because alloying with Hf increases the martensitic transformation temperatures $[37,38]$. Therefore, at room temperature the martensite must first appear in regions enriched in hafnium.

ii) TEM investigation: morphology and chemical composition of nanosized particles

TEM investigation of $\mathrm{Ti}-\mathrm{Ni}-\mathrm{Hf}$ powders obtained in liquid argon revealed that the finest particles with dimensions between 10 and $200 \mathrm{~nm}$ show a trend to form conglomerates (Fig. 2a). The largest particles are usually not completely transparent and have an evident fine structure, as easily seen on Fig. $2 b$. The typical features of these particles appear to be very similar to those observed for $\mathrm{Ti}-\mathrm{Ni}-\mathrm{Cu}-\mathrm{Zr}$ nanosized powders described in details elsewhere [29]. EDX analysis made for several agglomerates and at local points of the largest particles revealed that the finest particles contain large amounts of oxygen, besides the main alloying elements (see Table 1). Carbon, which usually appeared because carbon films were used as substrate for the powders, is not shown in the table. It is important to notice that the finest particles have stronger chemical heterogeneities and their composition differs from the composition of the master alloy.

The most important result is that the relative nickel content, which was calculated without taking into account the oxygen content, increases in the fine particles, while the relative contents of titanium and notably hafnium decrease in comparison with those in the bulk alloy (Table 1). If the nanosized fraction actually appears as a result of condensation of vapor phase, it means that the vapor containing $\mathrm{Ti}, \mathrm{Ni}$ and Hf molecules is enriched in nickel in comparison with titanium and especially hafnium.

iii) SEM investigation

a) Morphology and chemical composition of raw powders

The morphology of raw powders of $\mathrm{Ti}-\mathrm{Ni}-\mathrm{Cu}-\mathrm{Zr}$ was analyzed with a LEO 1530 instrument. Powder was poured onto a carbon conductive substrate. Most of the round particles sized between a few microns and 
Table 1 Results of EDX analysis of the nano-particles.

\begin{tabular}{l|c|c|c|c|c}
\hline Element/Line & $\mathrm{O}(\mathrm{K})$ & $\mathrm{Ni}(\mathrm{K})$ & $\mathrm{Ti}(\mathrm{K})$ & $\mathrm{Zr}(\mathrm{K})$ & $\mathrm{Hf}(\mathrm{K})$ \\
\hline Content, at.\% & $35.8 \pm 8.9$ & $40.9 \pm 7.0$ & $20.3 \pm 6.0$ & $0.4 \pm 0.5$ & $2.6 \pm 1.3$ \\
Relative content, at.\% & - & $64.1 \pm 7.0$ & $31.4 \pm 6.7$ & $0.6 \pm 0.9$ & $3.9 \pm 1.7$ \\
\hline
\end{tabular}
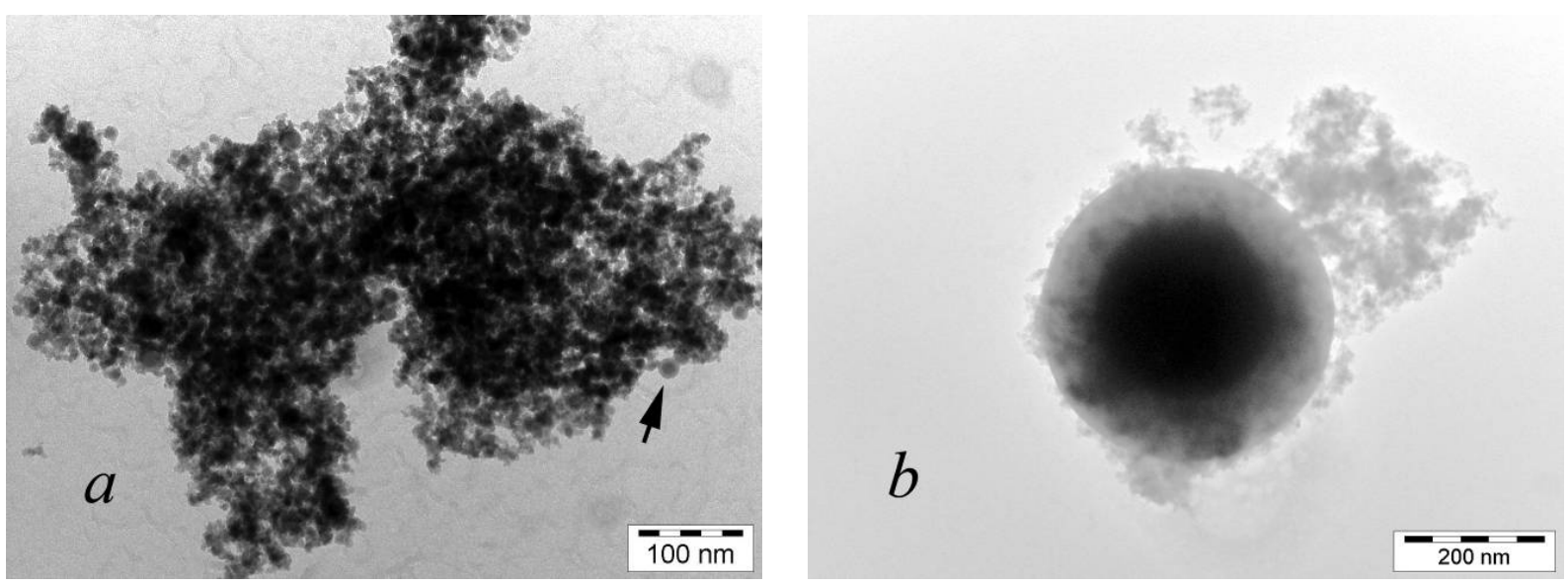

Fig. 2 Morphology of nanosized Ti-Ni-Hf spark erosion powder obtained in liquid argon. The arrow in $(a)$ and the photo $(b)$ show the internal structure of the particles.
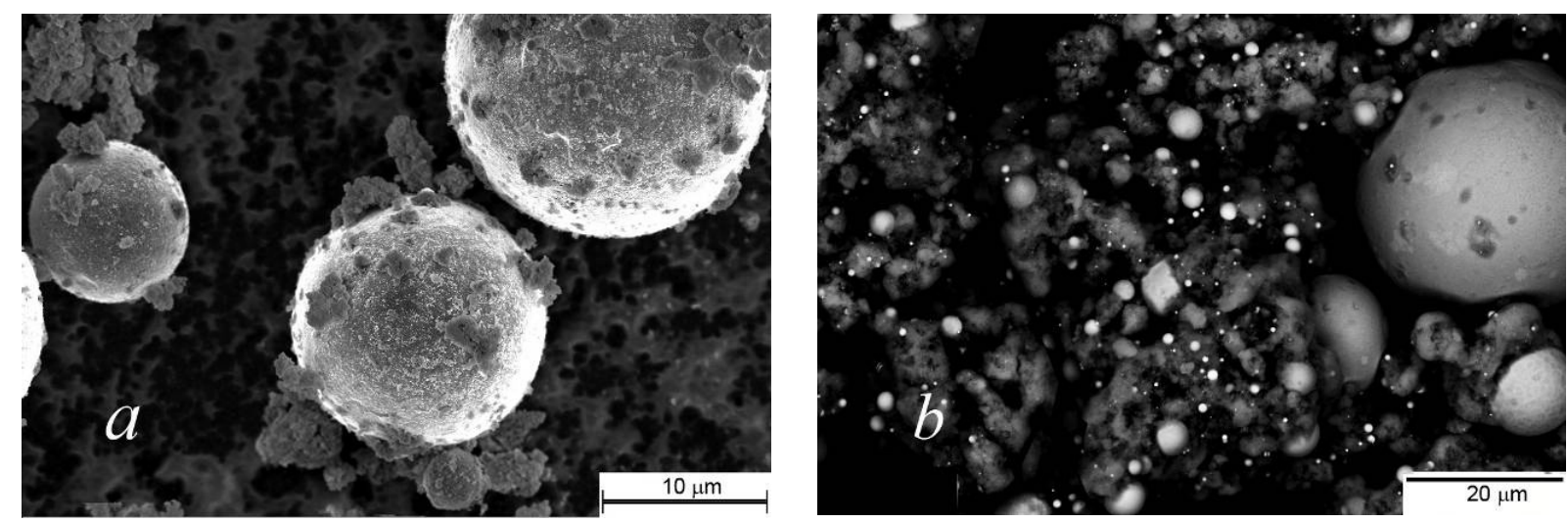

Fig. 3 Morphology of micron-sized Ti-Ni-Hf spark erosion powder obtained in liquid argon: $(a)$ powder poured on the carbon conductive substrate; $(b)$ the acetone suspension of powders treated in $\mathrm{H}_{2}$ poured on $\mathrm{Al}$ substrate.

$30-40 \mu \mathrm{m}$ were coated by clouds of fine particles (Fig. $3 a$ ). The compositions of such samples were not analyzed due to a significant charge effect.

To analyze the morphology and composition of Ti-Ni-Hf raw powder a JAMP-9500F instrument was used. The accelerating voltage was $15 \mathrm{kV}$. This value is sufficient to excite the $\mathrm{K}$ and $\mathrm{L}$ series of $\mathrm{Hf}$ and $\mathrm{Zr}$. At the same time the spatial distribution is better. The samples were obtained by pouring a suspension of powders in acetone onto an $\mathrm{Al}$ substrate. In this case the smallest particles were better separated, agglomerates of fine particles did not interfere and it was possible to make the chemical analysis even of the smallest particles (Fig. $3 b$ ). It was observed that the smaller the particles the brighter was their image, which evidences that the smallest particles contain more heavy elements, such as Hf, than the larger ones. Indeed, the dependence of the $\mathrm{Hf}$ content on the particle size is more significant in this case, as can easily be seen on Fig. 4.

b) Cross-section analysis of the chemical composition of powders

To study the internal structure and composition the powder was mixed with a polymer. The mixture was polished after stiffening. An SEM investigation of the cross-section of particles of $\mathrm{Ti}-\mathrm{Ni}-\mathrm{Cu}-\mathrm{Zr}$ powder, carried out with the LEO 1530 instrument, revealed a morphology transients between cellular and equiaxedtype with pronounced spherical symmetry Fig. $5 a$. In particular, small spots were mostly distributed in peripheral areas of the particle; grey boundaries, as well as lighter cells separated by these boundaries, 

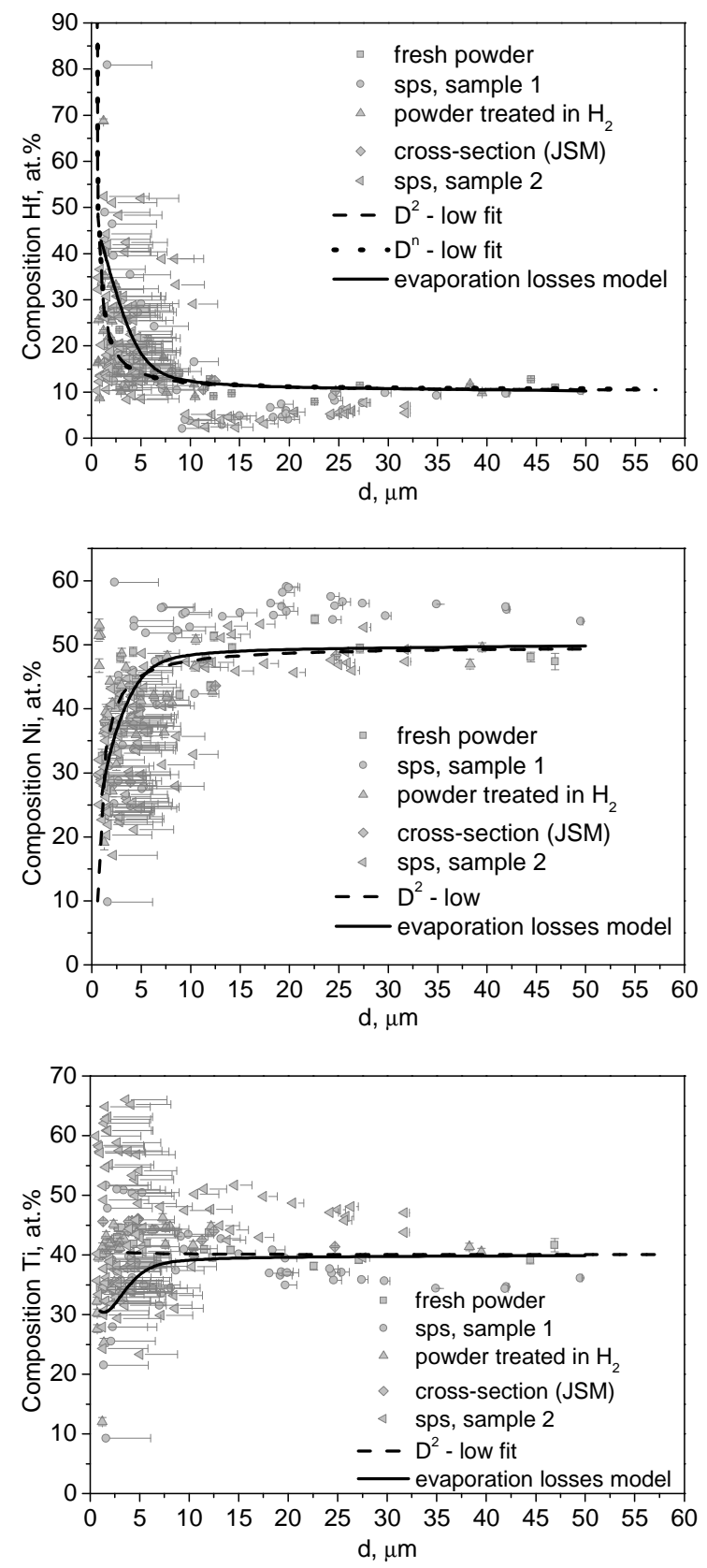

Fig. 4 Size dependences of the concentration of different elements in $\mathrm{Ti}-\mathrm{Ni}-\mathrm{Hf}$ powders obtained in liquid argon.

have a tendency to elongate in radial directions. Such symmetry indicates that the nucleation of solid phase starts from the central (internal) region of the particle and has mostly a single event feature. The microstructure peculiarities are too small (less than $1 \mu \mathrm{m})$ to permit their chemical analysis. However, if taking into account the X-ray data, we can suppose that the light areas have a composition close to equiatomic ( $\mathrm{Ti}, \mathrm{Zr}) \mathrm{Ni}$, corresponding to the B2 or B19' phase, while the dark spots have a composition close to $(\mathrm{Ti}, \mathrm{Zr})_{2} \mathrm{Ni}$, corresponding to the $\mathrm{Ti}_{2} \mathrm{Ni}$ phase, and the grey areas seem to be enriched in titanium. The total composition measured from areas on the cross- section of particles was close to that of the master alloys. Several measurements, made on particles sized 5 up to $50 \mu \mathrm{m}$, indicated a tendency towards an increase of the $\mathrm{Zr}$ content with decreasing particle size.

The SEM investigation of $\mathrm{Ti}-\mathrm{Ni}-\mathrm{Hf}$ powder carried out with the LEO 1530 instrument confirmed that the cross-section of the particles has a morphology very similar to that of the $\mathrm{Ti}-\mathrm{Ni}-\mathrm{Cu}-\mathrm{Zr}$ powder (Fig. $5 b$ ). In this case the peculiarities of the structure were smaller and instead of dark spots bright ones appear. One can suppose that the bright spots belong to a phase significantly enriched in hafnium. Radial symmetry of the cross-section of $\mathrm{Ti}-\mathrm{Ni}-\mathrm{Hf}$ particles was observed, as for the $\mathrm{Ti}-\mathrm{Ni}-\mathrm{Zr}-\mathrm{Cu}$ particles. This peculiarity presumes a single nucleation event of solid phase from the inner regions of the particles. The compositions of both powders are close to quasi-equiatomic. They can be described as $(\mathrm{Ti}, \mathrm{Zr})_{50}(\mathrm{Ni}, \mathrm{Cu})_{50}$ or $(\mathrm{Ti}, \mathrm{Hf})_{50} \mathrm{Ni}_{50}$ and are similar to a the TiNi intermetallic compound. This compound melts congruently at about $1600 \mathrm{~K}$ and, according to the binary phase diagram [39], a decrease of the nickel content decreases the melting temperature of the alloy. It is natural to assume that, because the nucleation of solid phase starts at the centre of the particle, the external (close to the boundary interface) regions contain less nickel. Unfortunately, this redistribution of Ni could not be observed because it was masked by subsequent redistributions, which take place during the cooling of the particles in the mushy state and are effectively observed.

The detailed chemical composition of the crosssection of $\mathrm{Ti}-\mathrm{Ni}-\mathrm{Cu}-\mathrm{Zr}$ particles was analyzed with a PEMMA-102 instrument with an accelerating voltage of $35 \mathrm{kV}$. In this case the minimal size of the particles available for the analyze was $3 \mu \mathrm{m}$. For particles of more than $30 \mu \mathrm{m}$ the mean of measurements made at three points on the surface of the particle was calculated and the statistical error was estimated. Only one measurement did not allow estimating the statistical error. Measurements of the total Ti, Ni and $\mathrm{Zr}$ contents in each of the particles, made with a JSM-6490LV instrument, confirmed the concentration-size dependence (Fig. 6). The point and area analyses were performed with high reliability. The accelerating voltage was $20 \mathrm{kV}$, which is enough to excite the $\mathrm{K}$ and $\mathrm{L}$ series of $\mathrm{Hf}$ and $\mathrm{Zr}$ and provide good spatial distribution (at least $1 \mu \mathrm{m}$ ). More pronounced results were obtained under the above mentioned conditions for the $\mathrm{Ti}-\mathrm{Ni}-\mathrm{Hf}$ powders. A large number of measurements, both area and point ones, were made for particles sized from 1 to $50 \mu \mathrm{m}$. The size dependences of the $\mathrm{Ti}, \mathrm{Ni}, \mathrm{Zr}$ and Hf contents are illustrated on Fig. 4 and Fig. 6.

c) Morphology and chemical composition of sintered powders

The morphology and chemical composition of spark plasma sintered $\mathrm{Ti}-\mathrm{Ni}-\mathrm{Hf}$ powder were analyzed with LEO 1530 and JAMP-9500F 

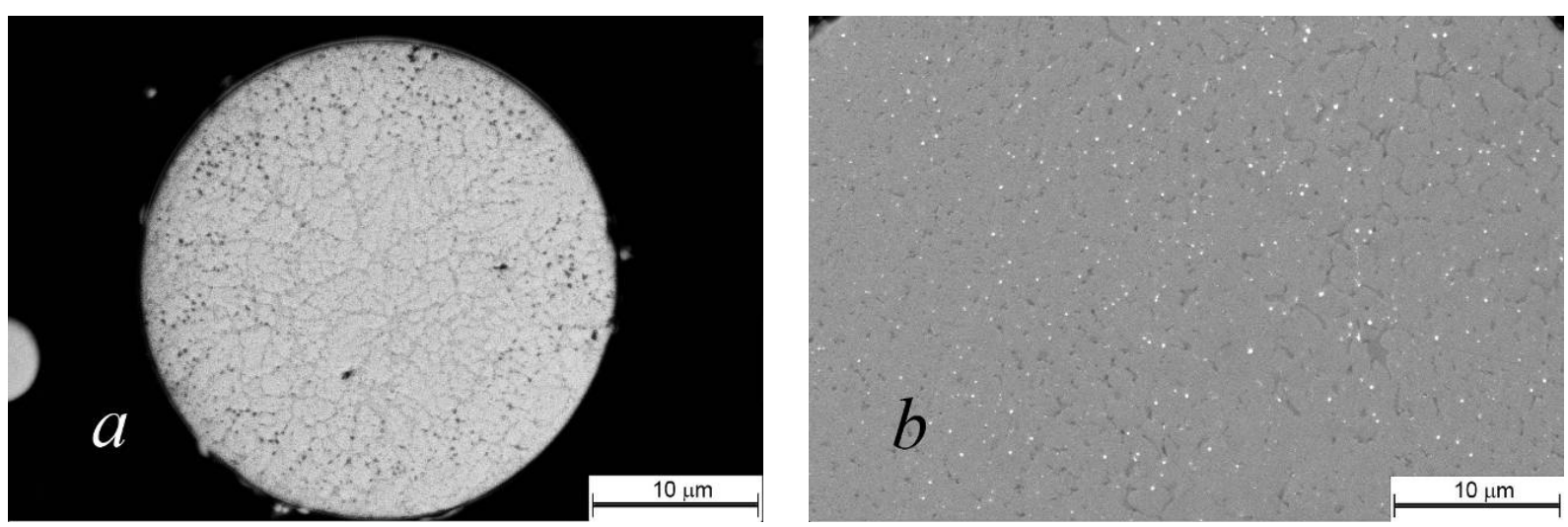

Fig. 5 Cross-section of micron-sized spark erosion powder obtained in liquid argon: (a) BSE image of a $\mathrm{Ti}-\mathrm{Ni}-\mathrm{Zr}-\mathrm{Cu}$ particle; (b) BSE image of a Ti-Ni-Hf particle sized about $100 \mu \mathrm{m}$.

instruments. Although the number of peculiarities, which appear in sintered powder, is the matter of another article, one of them should be noted here. The sintering process localized and clarified the hafnium distribution in the particles. The bright spots, which presumably correspond to hafnium-enriched areas, became pronounced (Fig. 7). The spots remained uniformly distributed in the largest particles. Their distribution is evidently not uniform in particles sized 1 to $20 \mu \mathrm{m}$. In addition all particles are coated by a bright shell, which is also enriched in hafnium. Taking into account the results of the X-ray analysis one can assume that all these peculiarities correspond to $\mathrm{HfO}_{2}$. This assumption was proved by a mapping analysis. It confirmed that the bright areas in the particles contain less nickel and titanium but a large amount of hafnium, as well as oxygen. It is evident from Fig. 7 that the smaller the particles, the brighter were their images. Thus the small particles contain a larger percentage of hafnium. Chemical analysis made for sintered samples are presented on Fig. 4. The spotted, non uniform distribution of hafnium provides some peculiarities on the size dependence of the $\mathrm{Ti}$ and $\mathrm{Hf}$ content (the gap between 10 and $30 \mu \mathrm{m}$ ). It was difficult to ensure measurement of the total element content, including the surface of the powder, and simultaneously avoid the influence of adjacent particles.

\section{Discussion}

\section{i) Accuracy of the SEM investigation}

To confirm the statistical reliability of the results presented on Fig. 4 and Fig. 6 the instrumental uncertainties were carefully evaluated. For the asprocessed powders poured on the substrate the actual particle size was measured and the uncertainties on the diameter correlate only with the particle nonsphericity. For the polished powders mixed with the polymer, as well as for the sintered powders, only the diameter of the particle cross-section was measured and not the actual size of the particle. In fact, some eventual cross-section of each particle was observed. Therefore the average observed radius and the average square of the radius were evaluated as:

$$
\begin{aligned}
& \langle R\rangle=\frac{1}{2 R_{0}} \int_{-R_{0}}^{R_{0}} \frac{R^{2} d R}{\sqrt{R_{0}^{2}-R^{2}}}=\frac{\pi}{4} R_{0} \\
& \left\langle R^{2}\right\rangle=\frac{1}{2 R_{0}} \int_{-R_{0}}^{R_{0}} \frac{R^{3} d R}{\sqrt{R_{0}^{2}-R^{2}}}=\frac{2}{3} R_{0}^{2}
\end{aligned}
$$

where $R_{0}$ is the actual particle radius, $R$ the observed cross-section radius, $\frac{1}{2 R_{0}}$ the probability of particle intersection at a particular place, which is assumed to be homogeneously distributed. The corresponding radius uncertainty is the following:

$$
\sigma=\sqrt{\left\langle R^{2}\right\rangle-\langle R\rangle^{2}} \approx 0.224 R_{0}
$$

In addition, the not uniform particle size distribution $F(R)$ (Fig. 8), which considers the probability of appearance of particles of different sizes in the field of view, should be taken into account:

$\sigma_{R}=0.224 \int_{R_{0}}^{\infty} R \cdot F(R) d R$

The particle size distribution diagram shows that the particles sized below $10 \mu \mathrm{m}$ dominate, although the mass (volume) part of the particles of about $40-50 \mu \mathrm{m}$ are most significant in the powder. Spikes at the large size edge of the distribution are caused by the poor representation of these values. It should be noted that the distribution maximum of atomized particles is usually shifted to values much larger than $10 \mu \mathrm{m}$ (Fig. 8).

The instrumental errors in measuring the concentrations of the alloy components in asprocessed powders are larger than for polished samples under the same conditions. This is due to the surface of the particles, which is not flat, and: 1) the excited X-ray radiation is emitted with different angles from different points of the particles; 2) backscattered electrons, secondary electrons and X-rays emitted 

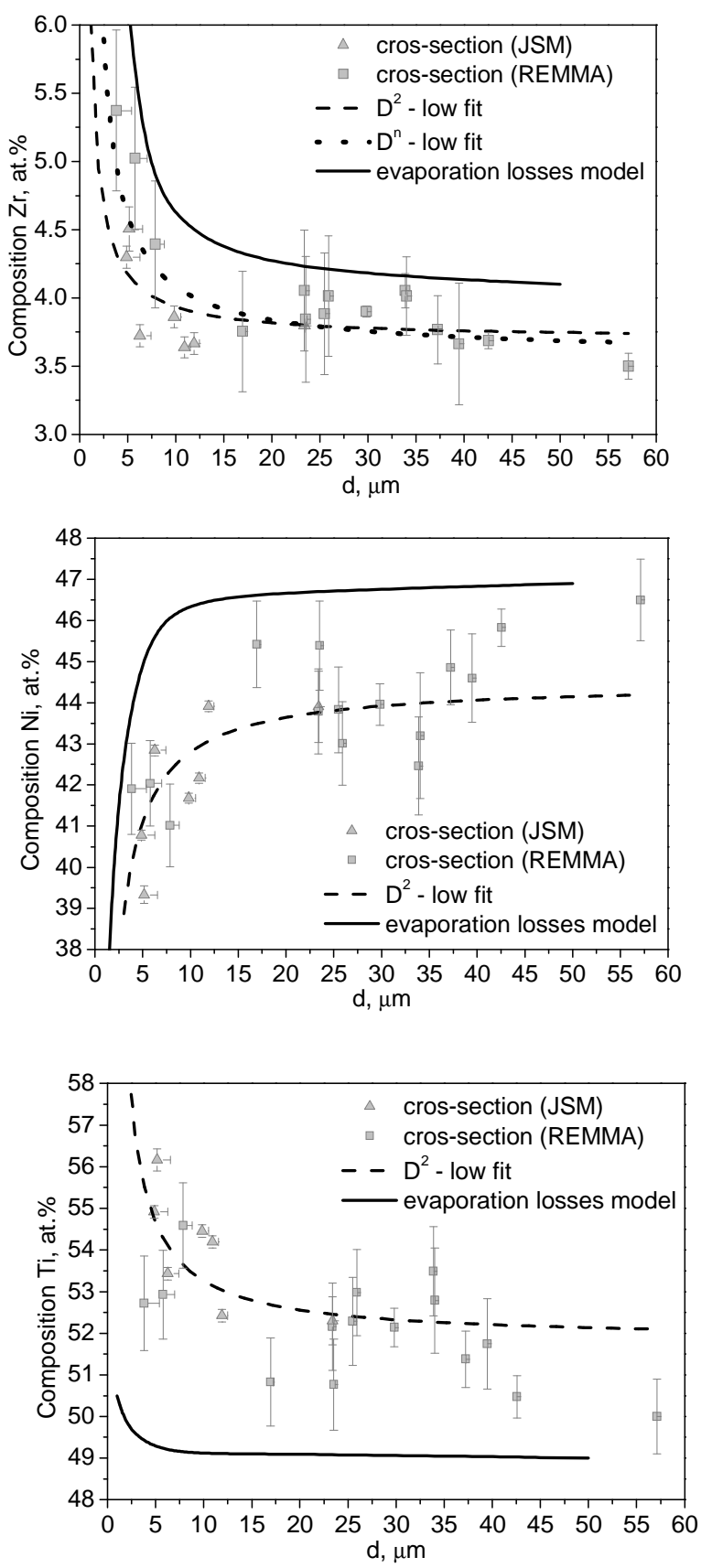

Fig. 6 Size dependences of the concentration of different elements in $\mathrm{Ti}-\mathrm{Ni}-\mathrm{Zr}-\mathrm{Cu}$ powders obtained in liquid argon.

from the particle excite the emission of surrounding particles, which reduces the local character of the analysis. The instrumental error of the PEMMA-102 equipment on the concentration was determined by the following expression:

$\sigma_{i}=\sqrt{\left(\sigma S_{i} \sum_{j \neq i}^{N} S_{j}\right)^{2}+S_{i}^{2} \sum_{j \neq i}^{N}\left(\sigma S_{j}\right)^{2}} /\left(\sum_{j=1}^{N} S_{j}\right)^{2}$

where $S$ is the area under the peak, $\sigma S$ the area error, the index $i$ refers a particular element. For the INCA
Energy 350 and INCA PentaFETx3 analyzers from the JSM-6490LV and JAMP-9500F equipment, respectively, the instrumental uncertainties are determined automatically by the program INCA Suite.

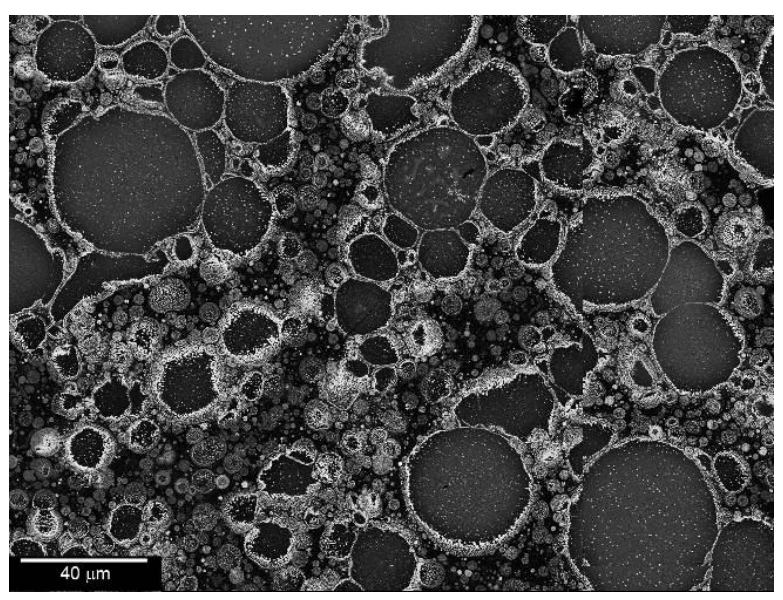

Fig. 7 BSE image of the sintered $\mathrm{Ti}-\mathrm{Ni}-\mathrm{Hf}$ powder. Light areas and spots correspond to $\mathrm{Hf}$ reached regions.

\section{ii) Correlation analyzes and mechanisms of particle formation}

Although both kinds of evaluated uncertainty are significant, the effect of the sharp variations of the chemical composition of the particles with decreasing radius is especially evident for the $\mathrm{Ti}-\mathrm{Ni}-\mathrm{Hf}$ powder, where the $\mathrm{Ni}$, $\mathrm{Hf}$, and $\mathrm{Zr}$ contents are changed monotonically, while the $\mathrm{Ti}$ content is not (Fig. 4, Fig. 6). To clarify the dependence of the element concentrations in the powder on the particle size obtained by means of different equipment and for different samples, a correlation analysis was carried out. The data were divided in two groups with particles above and below $10 \mu \mathrm{m}$, respectively. The results are presented in Table 2. Correlations with a significance level $p<0.05$ are marked in bold. Evidently the correlation in general is higher for groups of particles smaller than $10 \mu \mathrm{m}$, except for $\mathrm{Ti}$, for which the dependence on the size has, apparently, a peak near $5 \mu \mathrm{m}$. One can also note that the largest correlations are observed between different elements.

The correlation between different element contents is not a great surprise because the total percentage of the elements should always be one hundred. The decrease of nickel with decreasing size obviously increases the total amount of other elements. According to Fig. 4 and Fig. 6, one would expect the highest content of $\mathrm{Hf}$ and $\mathrm{Zr}$ in the smallest particles, i.e. the nanosized ones. However the observed situation is completely opposite. It means that the mechanisms for the formation of nanosized and micron-sized particles are accompanied by opposite trends. Evaporation losses accompanied the cooling of the micron-sized molten particles, while the nanosized 
Table 2 Correlation between the concentrations of different elements and between different particle diameters for a $\mathrm{Ti}-\mathrm{Ni}-\mathrm{Hf}$ powder obtained by spark erosion.

\begin{tabular}{c|c|c|c|c|c|c|c|c}
\hline & \multicolumn{4}{|c|}{$>10 \mu \mathrm{m}$} & \multicolumn{4}{c}{$<10 \mu \mathrm{m}$} \\
\cline { 2 - 9 } & $d$ & $\mathrm{Ti}$ & $\mathrm{Ni}$ & $\mathrm{Hf}$ & $d$ & $\mathrm{Ti}$ & $\mathrm{Ni}$ & $\mathrm{Hf}$ \\
\hline$d$ & 1 & $\mathbf{- 0 . 3 6}$ & 0.26 & 0.08 & 1 & 0.03 & $\mathbf{0 . 4 4}$ & $\mathbf{- 0 . 3 6}$ \\
$\mathrm{Ti}$ & $\mathbf{- 0 . 3 6}$ & 1 & $\mathbf{- 0 . 6 1}$ & $\mathbf{- 0 . 3 5}$ & 0.03 & 1 & $\mathbf{- 0 . 1 9}$ & $\mathbf{- 0 . 6 6}$ \\
$\mathrm{Ni}$ & 0.26 & $\mathbf{- 0 . 6 1}$ & 1 & -0.53 & $\mathbf{0 . 4 4}$ & $\mathbf{- 0 . 1 9}$ & 1 & -0.62 \\
$\mathrm{Hf}$ & 0.08 & $\mathbf{- 0 . 3 5}$ & $\mathbf{- 0 . 5 3}$ & 1 & $\mathbf{- 0 . 3 6}$ & $\mathbf{- 0 . 6 6}$ & $\mathbf{- 0 . 6 2}$ & 1 \\
\hline
\end{tabular}

Table 3 Some thermodynamic properties of the alloying elements. The vapor pressure was calculated for $3000 \mathrm{~K}$.

\begin{tabular}{l|c|c|c|c}
\hline Element & $\mathrm{Ni}$ & $\mathrm{Ti}$ & $\mathrm{Zr}$ & $\mathrm{Hf}$ \\
\hline$T_{B}, \mathrm{~K}$ & 3005 & 3560 & 4650 & 4876 \\
$\Delta H, \mathrm{~kJ} / \mathrm{mole}$ & 371.8 & 429.0 & 581.6 & 661.1 \\
$n_{\mathrm{v}}, 10^{25} \mathrm{~m}^{-3}$ & 0.240 & 0.014 & $0.04 \cdot 10^{-5}$ & $0.003 \cdot 10^{-5}$ \\
\hline
\end{tabular}
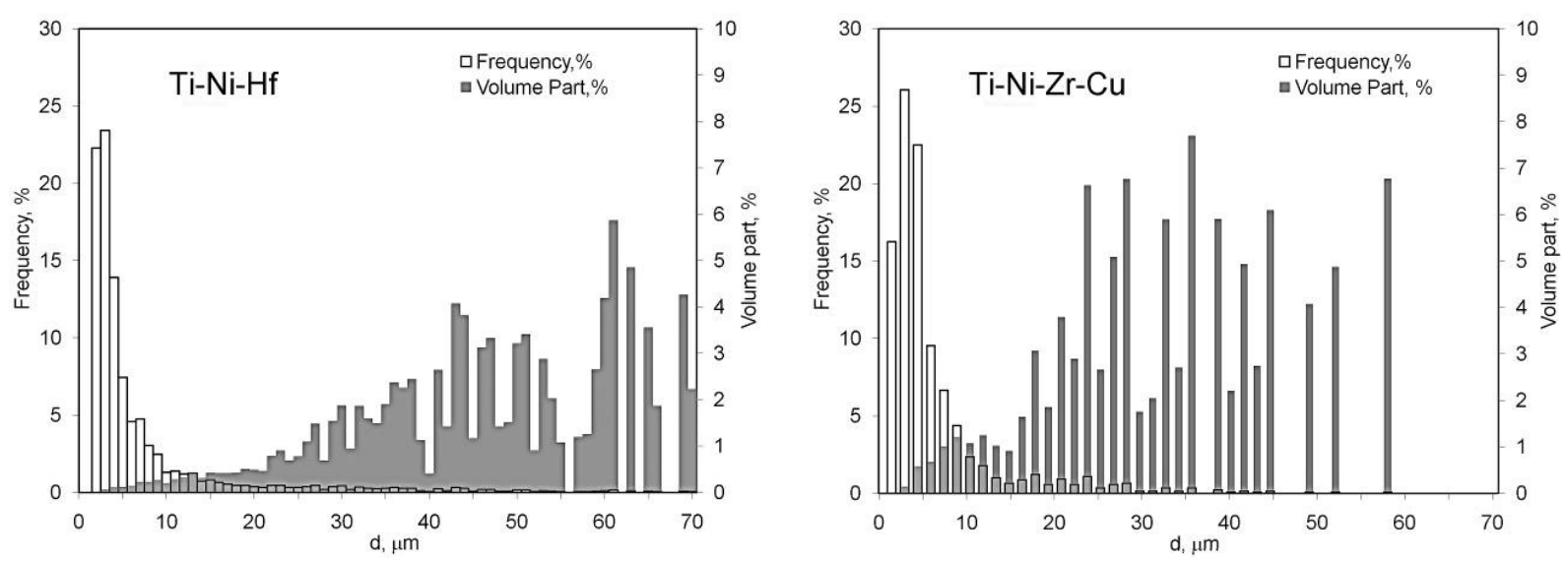

Fig. 8 Particle size distributions $F(R)$ for $\mathrm{Ti}-\mathrm{Ni}-\mathrm{Hf}$ and $\mathrm{Ti}-\mathrm{Ni}-\mathrm{Zr}-\mathrm{Cu}$ spark erosion powders.

ones appeared by condensation from the vapor remaining continuously in thermodynamic equilibrium with the vapor. The composition of the vapor phase is determined by the evaporation losses of micron- and submicron-sized particles.

The assumption that variations of the chemical composition are caused by the different rates of evaporation of the alloy components during the spark erosion processing is confirmed by comparing the vapor pressures of $\mathrm{Ni}, \mathrm{Ti}, \mathrm{Zr}$, and $\mathrm{Hf}$ at $3000 \mathrm{~K}$ (Table 3). The more significant the effect of the redistribution of the alloying component, the higher the temperature of the particle. Therefore only particles in the molten state will be considered further, since the main contribution to the composition variations corresponds to the presence of particles in the vicinity of the boiling temperature. The majority of the particles with such high temperatures are presumably formed by the mechanism of powder formation during a spark discharge. It consists of rapid heating, then volatile boiling of the bath of molten alloy on the surface of the chunks, followed by the ejection of molten particles into the surrounding liquid argon [17]. Due to the lack of data about the boiling point of $\mathrm{Ti}-\mathrm{Ni}-\mathrm{Hf}$ and $\mathrm{Ti}-\mathrm{Ni}-\mathrm{Zr}-\mathrm{Cu}$ alloys the evaluation of the vapor pressure was made for $3005 \mathrm{~K}$ (boiling point of $\mathrm{Ni}$ ), according to the well known formula:

$n_{v i}=\frac{P_{0}}{k_{b} T_{B}} \exp \left(\frac{\Delta H}{R}\left(\frac{1}{T_{B}}-\frac{1}{T}\right)\right)$

where $P_{0}$ is atmospheric pressure, $k_{b}$ is the Boltzmann constant, $\Delta H$ and $T_{B}$ are the latent heat and boiling temperature of the alloying element. The influence of the particle size on the changes of chemical composition will be more evident after having considered some models explaining this effect.

iii) Assumptions of analytical models

The key idea of the explanation of the effects observed is that different elements having drastically different saturation pressure evaporate from the surface of the molten droplets at different rates during the quenching 
in liquid argon. We can also consider that the effects of evaporations are more significant at high temperatures relatively close to the boiling temperature of the molten alloy. Two models of particle evaporation were developed. Both of them assume the following statements.

A) Evaporation of the elements from the surface occurs in vacuum. The possible influence of the carrier gas (argon) on the evaporation processes is ignored.

B) The density of the molten droplets remains constant during the evaporation.

C) The evaporation heat of the alloy components is assumed to be temperature independent.

D) The velocity of the particles is low and convective heat transfer is ignored. Thus, evaporation of the elements occurs primarily due to diffusion.

E) The components of the alloys do not affect each other in the process of evaporation. The perfect solid solution approximation is considered.

F) The elements evaporating from the particle surface are considered as an ideal gas.

iv) " $d^{2}$-law" model

The first model was developed to fit the experimental data points on Fig. 4 and Fig. 6 by extrapolating the curve in the best way. It presumes that the well-known " $d^{2}$-law" $[40,41]$ for the rate of evaporation is held:

$d^{2}=d_{0}^{2}-\lambda t$

where $\lambda$ is a constant for the alloy, $d$ and $d_{0}$ are the terminal (after exposure time $t$ ) and initial diameter of the evaporating particle, respectively. Keeping in mind the assumption B) the terminal concentrations of $\mathrm{Zr}$ and $\mathrm{Hf}$ in the particle are defined as follows:

$x_{Z r, H f}=\frac{N_{Z r, H f}}{N} \approx \frac{N_{0 Z r, H f}}{N}=x_{0 Z r, H f} \frac{V_{0}}{V}$

where $N_{0 Z r, H f}$, the starting quantities of $\mathrm{Zr}$ and $\mathrm{Hf}$ molecules, are approximately equal to the terminal $N_{Z r, H f}$ quantities. In (7) the $\mathrm{Zr}$ and $\mathrm{Hf}$ evaporation losses are neglected due to their large vaporization heat and low rate of evaporation (Table 3 ). $N$ is the total number of molecules in the particle. $V_{0}$ and $V$ are the initial and final volume of the molten (evaporating) particle. The mass loss due to evaporation of the $i$-th element is:

$\frac{\delta m_{i}}{\delta t}=\frac{\pi}{4} \rho_{l} \lambda_{i} d$

where $\rho_{l}$ is the density of the molten particle, $\lambda_{i}$ is the evaporation constant of the $i$-th species in the solution [40]:

$\lambda_{i}=\frac{4 \cdot S h \cdot \rho_{c} D_{i}}{\rho_{l}} \Delta w_{i}$

$S h$ is the Sherwood number, usually represented by the Ranz-Marshall correlation [42], which is approximately equal to 2 according to assumption $\mathrm{D}$ ). The density $\rho_{c}$ is the representative density and may be the average density of the evaporating elements between the surface and somewhere far from the surface of the particle. $D_{i}$ is the diffusion coefficient for the species $i, \Delta w_{i}$ is the difference between the mass fraction of the species $i$ on the surface and somewhere far from the particle. We can formally introduce the evaporation time $t$ as quadratic relative $d$. Taking into account that $V \sim d^{3}$ and representing the concentration of the elements as a function of the measured diameter $d$, we obtain:

$$
\begin{aligned}
& x_{Z r, H f}=x_{0 Z r, H f} \frac{\left(d^{2}+\lambda t\right)^{\frac{3}{2}}}{d^{3}}= \\
& x_{0 Z r, H f}\left((\lambda b+1)+\frac{\lambda a}{d}\right)^{\frac{3}{2}} \\
& x_{T i, N i}=\frac{x_{0 T i, N i}\left(d^{2}+\lambda t\right)^{\frac{3}{2}}-\frac{6}{\pi \rho_{l}} \int_{0}^{t} \frac{\delta m_{T i, N i}}{\delta t} d t}{d^{3}}= \\
& \left(x_{0 T i, N i}-\frac{6}{\pi} \frac{\lambda_{T i, N i}}{\lambda}\right)\left((\lambda b+1)+\frac{\lambda a}{d}\right)^{\frac{3}{2}}+\frac{6}{\pi} \frac{\lambda_{T i, N i}}{\lambda}
\end{aligned}
$$

where $a$ and $b$ are the coefficients of the quadratic evaporation time. The values $(\lambda b+1), \lambda a, \lambda_{i} / \lambda$ were fitted by the method of least squares. The results are presented by the solid line on Fig. 4 and Fig. 6 .

A similar fitting procedure was made with a less rigorous and more formal assumption that the " $d^{n}$-law" is valid. The exponent $n$ calculated by the least-squares method is close to $2(n=2.18 \pm 0.26$ for $\mathrm{Ti}-\mathrm{Ni}-\mathrm{Zr}$ and $n=2.08 \pm 0.47$ for Ti-Ni-Hf). Thus, we confirmed the applicability of the " $d^{2}$-law" for the systems under consideration, which means that the processes of varying the chemical composition are actually governed by the evaporation of species from the surface of the particles.

v) Model of evaporation losses of a superficial layer The second model of evaporation losses assumes, in addition, that the temperature gradient inside the particle is very small during the cooling, excepting perhaps a thin superficial layer. Only molten particles are considered because significant evaporation of element takes place only at high temperature close to the boiling temperatures. The thermal behavior of the molten particle can be described by a simple Newtonian formulation [43-46]:

$\frac{d T}{d t}=-\frac{12 k_{g}}{C_{l} \rho_{l} d^{2}}\left(T-T_{\text {env }}\right)-\frac{6 \varepsilon \sigma}{C_{l} \rho_{l} d}\left(T^{4}-T_{\text {env }}^{4}\right)$

where the first term corresponds to convection and the second one to heat radiation according to the StefanBoltzmann law. $C_{l}$ is the heat capacity of a molten droplet calculated in the Dulong-Petit approximation, $k_{\mathrm{g}}$ is the gas convective heat transfer coefficient given by the Ranz-Marshall relation [42], $k_{B}$ and $\sigma$ are the Boltzmann and Stefan-Boltzmann constants, respectively, $\varepsilon \approx 0.8$ is emissivity, $T_{e n v}$ is the temperature of liquid argon. The contribution of this term is significant at high temperatures, at which the evaporation losses should be especially great. The flux 
of evaporated molecules through the surface $S$ is calculated as:

$$
\frac{d N_{v a p, i}}{d t}=\frac{1}{4} n_{v a p, i}\left\langle v_{i}\right\rangle S
$$

where $N_{v a p, i}$ is the number of evaporated molecules, $n_{\text {vap }, i}$ is the density of the saturated vapor of the $i$-th element and $\left\langle v_{i}\right\rangle=\sqrt{\frac{8 k_{B} T}{\pi m_{i}}}$ the mean velocity of evaporated molecules of the species $i$. The density of the saturated vapor depends on the temperature and $q_{i}$ - the molar heat of vaporization of the species $i$. We assume that the density of the $i$-th component in the gaseous state is as follows:

$n_{v a p, i}=n_{i l} \exp \left\{-\frac{q_{i}}{R T}\right\}$

where $n_{i l}$ is the volume concentration of the $i$-th element within the molten particle.

Let us assume the existence of an effective evaporating superficial layer. Its width is limited by the diffusion of different elements inside the particle. It is very hard to observe this layer. As pointed out above, a possible redistribution of elements in such a layer, which could appear due to diffusion processes inside the particles, is completely ruined by the subsequent solidification processes. Therefore the thickness of the layer $l$ has been chosen as $1 \mu \mathrm{m}$ to better fit the experimental data. The volume concentration of the $i$-th element within the molten particle $n_{i l}$ is equal to:

$n_{i l}=\frac{N_{0 i}-N_{\text {vap }, i}}{V^{s f}}$

where $V^{s f}$ is the volume of the superficial layer. $N_{0 i}$ is the initial amount of the $i$-th species, which is calculated as:

$$
N_{0, i}=\frac{m_{0, i}}{\mu} N_{A}=\frac{\rho_{l} V_{0}^{s f}}{\mu} N_{A}
$$

Here $m_{0, i}$ is the initial total mass of the $i$-th species in the initial superficial volume $V_{0}^{s f}$. Taking together (13), (14) and (15) one can rewrite formula (12) as:

$$
\begin{aligned}
& \frac{d N_{\text {vap }, i}}{d t}= \\
& \frac{3}{2} d^{2} \frac{\left(\frac{\pi \rho_{l} N_{A}}{6 \mu}\left(d_{0}^{3}-\left(d_{0}-l\right)^{3}\right)-N_{v a p, i}\right)}{\left(d_{0}^{3}-\left(d_{0}-l\right)^{3}\right)} \times \\
& e^{-\frac{q_{i}}{R T}} \sqrt{\frac{8 k T}{\pi m_{i}}}, i=\overline{1,3}
\end{aligned}
$$

where $d$ and $d_{0}$ are the current and initial diameters of the particle. The changes of the diameter of the particle occurring during the evaporation can be calculated from the mass loss equation:

$$
\frac{d}{d t} d=-\frac{2 \mu}{\pi \rho_{l} N_{A} d^{2}}\left(\sum_{i=1}^{3} \frac{d N_{v a p, i}}{d t}\right)
$$

where $\mu$ (molecular weight of the alloy) is assumed to be constant. The following initial conditions were used:

$$
\begin{aligned}
& \left.N_{\text {vap }, i}\right|_{t=0}=0, i=\overline{1,3} \\
& \left.T\right|_{t=0}=T_{\max } \\
& \left.d\right|_{t=0}=d_{0}
\end{aligned}
$$$$
T_{\max } \text { was chosen equal to } 3000 \mathrm{~K} \text {, and the final }
$$
temperature $1583 \mathrm{~K}$ (Ti50-Ni50 melting point [39]). The latter is not so important because the rate of evaporation decreases rapidly with decreasing temperature and becomes negligibly small at the Ti50-Ni50 melting point. We obtain a system of five ordinary self-consistent differential equations ((11), (16), (17)) with five unknown values. The results of their numerical solution are presented on Fig. 4 and Fig. 6.

It is evident that the behavior of the $\mathrm{Zr}, \mathrm{Hf}$, and $\mathrm{Ni}$ concentrations is qualitatively well described by the model. At the same time the model is unable to explain the behavior of the titanium concentration, or make accurate predictions of the species content, especially in the case of the $\mathrm{Ti}-\mathrm{Ni}-\mathrm{Zr}$ powder. First of all the reasons for the size-concentration dependence are quite simple in principle. The flux of evaporated molecules (12), and consequently the change of species content, is proportional to the square of the diameter of the particle. At the same time the volume of the particle is proportional to the cube of the diameter. Then the concentration change is inversely proportional to the diameter, and as a consequence the particles of large diameters have chemical compositions close to the composition of the master alloy (see Fig. 4 and Fig. 6).

There are several peculiarities that complicate this rough speculation. The basics among them are the following: if the radiation emission term in formula (11) is omitted, as usually done in gas atomization models [47-54], the average cooling rate $C R$ of the molten particles can be represented in an invariant form as $C R \cdot d^{2}=$ const (diameter of the particles, $d$, in $\mu \mathrm{m}$ and cooling rate in $\mathrm{K} / \mathrm{s}$ ). In reality the constant in this representation depends on the diameter of the particle. For a particle of diameter $1 \mu \mathrm{m}$ it is equal to $4 \cdot 10^{7}$, while for a $100 \mu \mathrm{m}$-particle the constant is equal to $19 \cdot 10^{7}$. The obvious reason for this discrepancy is the different size dependence of the emission and convection terms in the expression for the cooling rate (11).

The conception of the effective evaporated superficial layer (16) requires taking into account the diffusion processes inside the molten particle. This may contribute significantly to the correction of the kinetics of the composition changes due to the different diffusivity of the species in the liquid alloy.

There exists a range of maximum temperature of the particles, from which the quenching in liquid argon is performed. The maximum starting temperature is the boiling temperature of the alloy, which is not known exactly. It is quite possible that 
particles of different sizes have different starting temperatures. It appears very plausible that the smaller the particle the more their maximum temperature and chemical composition vary.

Finally, in order to make the model more adequate, one must keep in mind that each of the molten micronsized particles is surrounded by a gaseous shell due to the evaporation of liquid argon. Obviously, formula (11) does not take into account the dynamics of this gaseous shell, the internal convections of the evaporating argon inside the shell, or the finite value of the velocity of the particle itself.

\section{Conclusions}

1) $\mathrm{Ti}-\mathrm{Ni}-\mathrm{Zr}-\mathrm{Cu}$ and $\mathrm{Ti}-\mathrm{Ni}-\mathrm{Hf}$ powders with particles sized from several tens of microns down to $10 \mathrm{~nm}$ were produced by the spark erosion method in liquid argon. As-processed powder particles with typical sizes between 1 and $50 \mu \mathrm{m}$ have round shape. Agglomerates of nanosized particles cover the micronsized particles. The internal structure of the particles has a morphology that is transient between cellular and equiaxed-type, with a pronounced spherical symmetry. Such symmetry indicates that nucleation of the solid phase appears from the central (internal) region of the particle and has a mostly single event feature.

2) Both kinds of powder contain the B2 phase, monoclinic (martensite) phase B19' and $\eta$ phase $\mathrm{Ti}_{2} \mathrm{Ni}$. Ti-Ni-Hf powder consists of $44 \pm 5 \mathrm{vol} . \%$ of martensitic phase, $35 \pm 4$ vol.\% of austenitic B2-phase and about $21 \pm 3$ vol. $\%$ of $\eta$ phase. After spark erosion processing of the $\mathrm{Ti}-\mathrm{Ni}-\mathrm{Hf}$ powder, the dominating phase in the powder spectra was monoclinic $\mathrm{HfO}_{2}$.

3) The particles of the Ti-Ni-Hf powder with sizes between 10 and $100 \mathrm{~nm}$ have round shape and show a fine structure. The nickel content in such fine particles is larger, whereas the content of titanium, and notably hafnium, is smaller than in the master alloy. This difference provides evidence that nanosized particles appear due to condensation from the vapor phase, which is enriched in $\mathrm{Ni}$ but contains less $\mathrm{Ti}$ and especially Hf.

4) Micron-sized particles of both powders are chemically inhomogeneous. The average composition of the particles demonstrates size dependence: while the amounts of $\mathrm{Hf}$ and $\mathrm{Zr}$ increase drastically, the amount of $\mathrm{Ni}$ decreases and the concentration of $\mathrm{Ti}$ demonstrates a complex behavior with decreasing particle size. The drastic change of the chemical composition is caused by the different rates of evaporation of the alloy components during the spark erosion process.

5) The models developed to describe the evaporation losses of the powder particles assume rapid quenching of the particles in cold argon and velocities of the powders close to zero, and ignore external convection cooling of the particles. The concentration-size dependencies are fitted satisfactorily in the assumption that the " $d^{2}$-law" of evaporation rate is held.

6) The average cooling rates $C R$ evaluated for molten particles quenched in liquid argon can be roughly represented in the invariant form as $C R_{x s} \cdot d^{2}=$ const.

7) $\mathrm{Ti}-\mathrm{Ni}-\mathrm{Hf}$ powders were sintered by the spark plasma sintering method. The micron-sized particles were oxidized, and the quantities of oxides were higher in particles with sizes below $10 \mu \mathrm{m} . \mathrm{HfO}_{2}$ oxide was mainly found in the spark plasma sintered samples.

\section{Acknowledgements}

The authors are grateful to the CNRS PICS-3717 project for supporting this work. The authors also thank Tokyo Boeki CIS LTD for giving the opportunity to carry out detailed scanning microscopy studies.

\section{References}

[1] A. Zambon, B. Badan, Mater. Sci. A 226-228 (1997) 119-123.

[2] H. Tomochika, H. Kikuchi, T. Araki, M. Nishida, Mater. Sci. A 356 (2003) 122-129.

[3] A. Ibarra, P.P. Rodriguez, V. Recarte, J.I. PérezLandazábal, M.L. Nó, J. San Juan, Mater. Sci. A 370 (2004) 492-496.

[4] G.A. Porter, P.K. Liaw, T.N. Tiegs, K.H. Wu, Scr. Mater. 43 (2000) 1111-1117.

[5] W. Maziarz, J. Dutkiewicz, J. Van Humbeeck, T. Czeppe, Mater. Sci. A 375-377 (2004) 844-848.

[6] G.A. Porter, P.K. Liaw, T.N. Tiegs, K.H. Wu, Scr. Mater. 43 (2000) 1111-1117.

[7] Zhu Li-Huia, Huang Qing-Weib, Mater. Lett. 57 (2003) 4070-4073.

[8] Y. Liu, J. Zhang, L. Yu, G. Jia, C. Jing, S. Cao, J. Magn. Magn. Mater. 285(1-2) (2005) 138-144.

[9] Y. Fu, C. Shearwood, Scr. Mater. 50 (2004) 319-323.

[10] F. Tepper, Powder Metall. 43(4) (2000) 320-322.

[11] S.K. Pabi, B.S. Murty, Mater. Sci. \& Eng. A 214 (1996) 146-152.

[12] X.G. Li, T. Murai, T. Aaito, S. Takahashi, J. Magn. Magn. Mater. 190 (1998) 277-288.

[13] Z. Wang, A.L. Fan, W.H. Tian, Y.T. Wang, X.G. Li, Mater. Lett. 60 (2006) 2227-2231.

[14] G.E. Monastyrsky, P.A. Yakovenko, V.I. Kolomytsev, Yu.N. Koval, A.A. Shcherba, R. Portier, Mater. Sci. Eng. A 481-482 (2008) 643-646.

[15] A.E. Berkowitz, M.F. Hansen, F.T. Parker, K.S. Vecchio, F.E. Spada, E.J. Lavernia, R. Rodriguez, J. Magn. Magn. Mater. 254-255 (2003) 1-6.

[16] G.E. Monastyrsky, V.V. Odnosum, 
V.I. Kolomytsev, Yu.N. Koval, P. Ochin, R. Portier, A.A. Shcherba, S.N. Zaharchenko, Metallofiz. Noveishie Tekhnol. $30 \quad$ (2008) 761-772 (in Ukrainian).

[17] J. Carrey, H.B. Radousky, A.E. Berkowitz, J. Appl. Phys. 95 (2004) 823-829.

[18] A.E. Berkowitz, H. Harper, D.J. Smith, H. Hu, Q. Jiang, V.C. Solomon, H.B. Radousky, Appl. Phys. Lett. 85(6) (2004) 940-942.

[19] A.E. Berkowitz, J.D. Livingston, J.L. Walter, J. Appl. Phys. 55 (1984) 2106-2108.

[20] Y.J. Tang, F.T. Parker, H. Harper, A.E. Berkowitz, Q. Jiang, D.J. Smith, M. Brand, F. Wang, IEEE Trans. Magn. 40(4) (2004) 2002-2004.

[21] O. Schneeweiss, Y. Jirásková, P. Řepa, Proc. Natl. Conf. Nano '02, Brno, Czech Republic, 2002, p. 105-107.

[22] H. Wan, A.E. Berkowitz, Scr. Metall. Mater. 32 (1995) 1827-1831.

[23] J.I. Hong, V.C. Solomon, D.J. Smith, F.T. Parker, E.M. Summers, A.E. Berkowitz, Appl. Phys. Lett. 89(14) (2006) 142506.

[24] M.S. Hsu, M.A. Meyers, A. Berkowitz, Scr. Metall. Mater. 32 (1995) 805-808.

[25] V. Solomon, D.J. Smith, Yun Jun Tang, A.E. Berkowitz, J. Appl. Phys. 95 (2004) 6954-6956.

[26] G.E. Monastyrsky, A.P. Shpak, Yu.N. Koval', R.Ya. Musienko, Metallofiz. Noveishie Tekhnol. 6(25) (2003) 803-816 (in Ukrainian).

[27] G.E. Monastyrsky, Yu.N. Koval', A.P. Shpak, R.Ya. Musienko, V.I. Kolomytsev, A.A. Scherba, S.N. Zaharchenko, P.G. Yakovenko, Poroshk. Metall. 5(6) (2007) 3-15 (in Russian).

[28] G.E. Monastyrsky, V.I. Kolomytsev, Yu.N. Koval', A.A. Scherba, S.M. Zaharchenko, R. Portier, Nanosist. Nanomater. Nanotekhnol. 5(2) (2007) 54-60 (in Ukrainian).

[29] O.M. Ivanova, M.I. Danylenko, G.E. Monastyrsky, V.I. Kolomytsev, Yu.N. Koval', A.A. Scherba, S.M. Zaharchenko, R. Portier, Metallofiz. Noveishie Tekhnol. 31(5) (2009) 603-614 (in Ukrainian).

[30] Y. Jirásková, S. Havlícek, O. Schneeweiss, V. Peřina, C. Blawert, J. Magn. Magn. Mater. 234 (2001) 477-488.

[31] E.D. Cabanillas, M. López, E.E. Pasqualini, D.J. Cirilo Lombardo, J. Nucl. Mater. 324 (2004) 1-5.

[32] A.E. Berkowitz, J.L. Walter, Mater. Sci. \& Eng. A 55 (1982) 275-287.
[33] G.Ya. Kolbasov, A.I. Ustinov, A.A. Shcherba, A.Ye. Perekos, M.O. Danilov, N.V. Vyunova, S.N. Zakharchenko, G. Hossbah, J. Power Sources 150 (2005) 276-281.

[34] A.A. Scherba, A.D. Podoltsev, I.N. Kucheryavaya, Tekhn. Elektrodin. 6 (2004) 4-17 (in Russian).

[35] Z.A. Munir, U. Anselmi-Tamburini, M. Ohyanagi, J. Mater. Sci. 41 (2006) 763-777.

[36] A.M. Locci, R. Orrù, G. Cao, Z.A. Munir, Intermetallics 11 (2003) 555-571.

[37] X.D. Han, W.H. Zou, R. Wang, Z. Zhang, D.Z. Yang, Acta Mater. 44(9) (1996) 3711-3721.

[38] J.H. Mulder, Ph.D. Thesis, Univ. Twente, Netherlands, 1994.

[39] J.L. Murray, Ni-Ti (Nickel-Titanium), In: T.B. Massalski (Ed.), Binary Alloy Phase Diagrams, 2nd ed., 1990, Vol. 3, pp. 2874-2876.

[40] C.T. Crowe, M. Sommerfeld, Y. Tsuji, Multiphase Flows with Droplets and Particles, CRC Press, 1998, p. 471.

[41] G. Aguilar, B. Majaron, W. Verkruysse, Y. Zhou, J.S. Nelson, E.J. Lavernia, Int. J. Heat Mass Transfer 44(17) (2001) 3201-3211.

[42] W.E. Ranz, W.R. Marshall, Chem. Eng. Proc. 58 (1952) 141-154.

[43] N. Zeoli, S. Gu, Comput. Mater. Sci. 43 (2008) 268-278.

[44] N. Zeoli, S. Gu, S. Kamnis, Int. J. Heat Mass Transfer 51 (2008) 4121-4131.

[45] S. Li, P. Wu, W. Zhoua, T. Ando, Mater. Sci. Eng. A 473 (2008) 206-212.

[46] S. Li, P. Wu, H. Fukud, T. Ando, Mater. Sci. Eng. A 499 (2009) 396-403.

[47] G. Vedovato, A. Zambon, E. Ramous, Mater. Sci. Eng. A 304-306 (2001) 235-239.

[48] R. Heringer, Ch.-A. Gandin, G. Lesoult, H. Henein, Acta Mater. 54 (2006) 4427-4440.

[49] J.B. Haelssig, A.Y. Tremblay, J. Thibault, S. Gh. Etemad, Int. J. Heat Mass Transfer 53, 19-20 (2010) 3947-3960.

[50] Ch.-A. Gandin, S. Mosbah, Th. Volkmann, D.M. Herlach, Acta Mater. $56 \quad$ (2008) 3023-3035.

[51] C.G. Levi, R. Mehrabian, Metall. Trans. A 13 (1982) 221-234.

[52] B.M. Michaelis, D. Dunn-Rankin, R.F. Smith Jr., J.E. Bobrow, Int. J. Heat Mass Transfer 50 (2007) 4554-4558.

[53] Q. Xu, E.J. Lavernia, Acta Mater. 49 (2001) 3849-3861.

[54] N. Zeoli, S. Gu, Comput. Mater. Sci. 38 (2006) 282-292. 